\title{
ANÁLISE E PROJETO ERGONÔMICO: UM NOVO OLHAR SOBRE O GUIDÃO DA MOTOCICLETA EM UM ESTUDO DE CASO
}

\section{ERGONOMIC DESIGN AND ANALYSIS: A NEW LOOK AT THE MOTORCYCLE HANDLEBAR IN A CASE STUDY}

\author{
Gabriel Miranda Silva ${ }^{1}$, Bacharelando. \\ Bruno Xavier da Silva Barros², M.Sc. \\ (1) universidade Federal de Pernambuco \\ e-mail: gmsilvabg18@hotmail.com \\ (2) Universidade Federal de Pernambuco \\ e-mail: barros_bruno@hotmail.com
}

Palavras-chave: ergonomia, produto, guidão.

\begin{abstract}
A referente pesquisa apresenta a análise ergonômica da atividade de um mototaxista, visando a sugestão conceitual para o reprojeto do guidão da motocicleta. Para tanto, lançou-se mão de etapas da Metodologia de Intervenção Ergonomizadora do Sistema Humano-Tarefa-Máquina, a qual conduziu a investigação e a elaboração dos requisitos projetuais e proposta conceitual do redesign.
\end{abstract}

\section{Key-words: Ergonomics, product, handlebars}

This research presents the ergonomic analysis of the activity of a mototaxista aiming the conceptual suggestion for the design of the motorcycle handlebars. In order to do so, it was used some steps of the Ergonomizing Intervention Methodology of the Human-Task-Machine System, which systematized the investigation and elaboration of the design requirements and conceptual proposal of redesign.

\section{INTRODUÇÃ̃O}

Segundo dados do IBGE, em 2015, existiam 20 milhões de motocicletas circulando pelo Brasil (IBGE, 2015). Se considerarmos dois usuários por veículo, seriam 40 milhões de indivíduos brasileiros os quais se pode lançar atenção. Cabe lembrar que os dados do IBGE revelam informações datadas de 2015 , interferências no poder de compra populacional pode ter elevado este número de usuários até o ano de 2017.

Uma das dificuldades vivenciadas pelos mototaxistas analisados diz respeito a fatores gerenciais, é uma atividade que oferece diversos riscos ao seu trabalhador, tal qual o estresse decorrente do âmbito veloz do seu trabalho, o cansaço gerado é consideravelmente desgastante. A 


\section{$16^{\circ}$ \\ ERGODESIGN USIHC CINAHPA}

perda do controle da moto, a redução na perceptibilidade do ambiente, a demora nas reações às ações do ambiente e as dores osteomusculares são alguns dos problemas que a sobrecarga gerada pela atividade pode causar.

Sob a égide das preocupações da Ergonomia do Produto, aliadas à crescente demanda por utilizações de veículos ciclomotores, este trabalho tem como objetivo analisar e propor uma alternativa ergonômica para o guidão de um modelo de motocicleta a partir de evidenciação de elementos prejudiciais à saúde física e mental do seu usuário.

Entendendo-se as inúmeras possibilidades para este tipo de análise, sejam os modelos de guidão ou os modelos de motocicletas, fez-se necessária a realização de um estudo de caso. Desta forma, para esta pesquisa, foi analisada a atividade de mototaxista de uma cidade pernambucana, a qual possui 58.000 habitantes e, devido ao custo acessível do veículo e das tarifas de serviço, lança mão desta atividade para a locomoção de passageiros. A motocicleta utilizada na cidade é do modelo Yamaha YRB de 125 cilindradas.

\section{FUNDAMENTAÇÃO TEÓRICA}

Para a elaboração de sistemas de pegas e manípulos, os dados dimensionais do corpo se fazem extremamente necessários. Neste sentido, Panero e Zelnik (2008) oferecem dados antropométricos em centímetros, os quais podem ser relevantes para o desenvolvimento de guidões para motocicletas. Os números dos autores referem-se a homens e mulheres, revelando do $5 \%$ il até o $95 \%$ il como pode ser acompanhado no quadro a seguir..

Quadro 1: Medidas antropométricas relevantes para projetos de guidões (dimensões em centímetros).

\begin{tabular}{ccc}
\hline MEDIDAS & $\begin{array}{c}\text { HOMENS } \\
\mathbf{5 \%} \text { il - 95\%il }\end{array}$ & $\begin{array}{c}\text { MULHERES } \\
\mathbf{5 \%} \% \mathbf{- 9 5 \%}\end{array}$ \\
\hline $\begin{array}{c}\text { Largura Cotovelo a } \\
\text { Cotovelo }\end{array}$ & $34,8-50,5$ & $31,2-40,9$ \\
$\begin{array}{c}\text { Altura de Descanso } \\
\text { de Cotovelo }\end{array}$ & $18,8-29,5$ & $18,0-27,9$ \\
Largura dos & $44,2-52,6$ & $37,8-43,2$ \\
\hline
\end{tabular}

$16^{\circ}$ Ergodesign - Congresso Internacional de Ergonomia e Usabilidade de Interfaces Humano Tecnológica: Produto, Informações Ambientes Construídos e Transporte

$16^{\circ}$ USIHC - Congresso Internacional de Ergonomia e Usabilidade de Interfaces Humano Computador

CINAHPA | 2017 - Congresso Internacional de Ambientes Hipermídia para Aprendizagem.

\begin{tabular}{|c|c|c|}
\hline Ombros & & \\
\hline $\begin{array}{c}\text { Alcance Frontal } \\
\text { Alongado }\end{array}$ & $82,3-97,3$ & $75,2-92,2$ \\
\hline $\begin{array}{c}\text { Alcance Frontal de } \\
\text { Apreensão }\end{array}$ & $75,4-88,9$ & $67,6-80,5$ \\
\hline $\begin{array}{c}\text { Comprimento da } \\
\text { Mão }\end{array}$ & $17,8-20,5$ & \\
\hline $\begin{array}{l}\text { Comprimento da } \\
\text { Palma da Mão }\end{array}$ & $10,0-11,8$ & \\
\hline $\begin{array}{c}\text { Largura da Palma } \\
\text { da mão }\end{array}$ & $8,0-11,1$ & \\
\hline $\begin{array}{c}\text { Largura dos dedos } \\
\text { juntos exceto o } \\
\text { polegar } \\
\end{array}$ & $8,2-9,6$ & \\
\hline
\end{tabular}

\section{PROCEDIMENTOS METODOLÓGICOS ADOTADOS}

Para a condução do estudo no acompanhamento analítico da atividade, lançou-se mão de etapas da Metodologia de Intervenção Ergonomizadora do Sistema Humano-TarefaMáquina, encontradas em Moraes e Mont'Alvão (2010). Neste sentido, foi realizada a fase de Sistematização Ergonômica, identificando o sistema-alvo e a modelagem comunicacional do sistema. Também se aplicou a etapa de Problematização Ergonômica, identificando flagrantes de incoerências de ordem físicas, cognitivas e organizacionais. Em complemento, também se realizou observações sistemáticas e assistemáticas; entrevistas estruturadas e semiestruturadas; questionários e aplicação da escala de desconforto postural de Corlett.

Durante o período de cinco dias de maior movimento urbano na cidade (segunda à sextafeira) a atividade de um mototaxista foi acompanhada em toda a sua jornada de trabalho diário, promovendo o desempenho analítico conduzido pela metodologia selecionada.

\section{RESULTADOS}

\subsection{Resultados do Questionário}

A aplicação do questionário evidenciou que o usuário realiza esta mesma função há 20 anos, trabalhando por até 12 horas diárias e não realizando nenhuma outra atividade profissional. Este fato nos fez entender que, há 20 anos o 


\section{$16^{\circ}$ \\ ERGODESIGN USIHC CINAHPA}

$16^{\circ}$ Ergodesign - Congresso Internacional de Ergonomia e Usabilidade de Interfaces Humano Tecnológica: Produto, Informações Ambientes Construídos e Transporte

$16^{\circ}$ USIHC - Congresso Internacional de Ergonomia e Usabilidade de Interfaces Humano Computador

CINAHPA | 2017 - Congresso Internacional de Ambientes Hipermídia para Aprendizagem. indivíduo vem realizando o mesmo exercício, requisitando os mesmos grupos musculares em um trabalho estático exaustivo e perigoso, que, inclusive, já causou problemas a ele, gerando um afastamento de 3 meses do serviço.

Identificou-se que o usuário não faz uso de medicamentos, porém, nos últimos 30 dias, vem sentindo dores de cabeça, nos ombros e, principalmente, no punho e nas costas. Com relação à ausência do trabalho mencionada anteriormente, houve apenas uma ocorrência, devido a fortes dores no punho.

Quando questionado sobre uma hierarquização das dores corporais, iniciando pelo incômodo de maior intensidade, o usuário elencou as seguintes partes do corpo: punho, pés, ombro, costas e cabeça. Em se tratando do ambiente do trabalho, o entrevistado afirmou ter boa relação com os colegas e com a família, não relatando problemas.

De um modo geral, o mototaxista se mostrou consideravelmente frustrado com seu emprego, afirmando que anseia abrir mão da atividade visando algo que implique em menos danos físicos e mentais.

\subsection{Resultados da Escala de Corlett}

O acompanhamento feito por meio da Escala de Corlett demonstrou que, com o passar do dia, as dores do punho e do pé foram as mais significativas, se agravando do nível 1 até o 4 no punho e do nível 1 até o 3 no pé. Ombros, cabeça e costas foram regiões que demonstraram dores no horário do meio dia, mas não aumentaram após a pausa para o almoço, elas permaneceram no mesmo nível. É válido ressaltar que, dependendo da demanda de transporte de passageiros do dia (que chega a somar uma média de 35 indivíduos), a sobrecarga muscular pode vir a se revelar ainda mais intensa.

\subsection{Problematização Ergonômica}

Na fase de Problematização Ergonômica foi feita a identificação e análise de situações flagrantes na atividade de uso do guidão. Esta fase se revelou uma das mais importantes, porque, por vezes, nem mesmo o usuário é capaz de identificar, em si mesmo, os problemas que assume durante o uso do produto e apenas a aplicação de um questionário pode não ser suficiente para denotar os problemas existentes. Desta forma, nessa fase de observação comportamental, pode-se não somente verificar o que o usuário afirmou em entrevistas, como também apontar novos problemas e procurar soluções para estes. A figura 1 (A e B), que se segue, sintetiza os principais pontos observados na fase de problematização ergonômica realizada.

Figura 1 A e B: Flagrantes de problema interfacial, instrumental, acional e informacional.
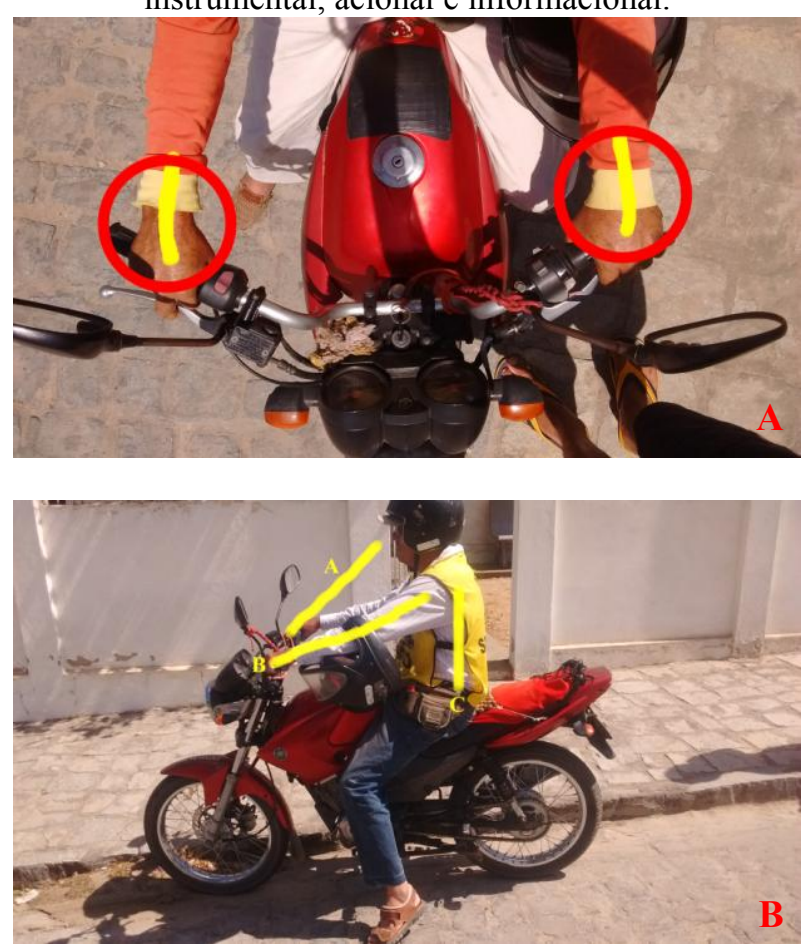

Fonte: Capturado pelo autor para a pesquisa.

A posição do guidão faz com que o usuário desvie seu punho para poder pilotar a moto. Os botões, por causa dessa má estrutura do guidão, não se encontram em locais estratégicos para acionamento e exigem demais dos dedos que já não estão em posição consideravelmente boa, visto o desvio ulnar, desvio esse causado quando a mão é desviada em direção ao osso ulna presente no antebraço e tal desvio pode levar ao 


\section{$16^{\circ}$ \\ ERGODESIGN USIHC CINAHPA}

$16^{\circ}$ Ergodesign - Congresso Internacional de Ergonomia e Usabilidade de Interfaces Humano Tecnológica: Produto, Informações Ambientes Construídos e Transporte

$16^{\circ}$ USIHC - Congresso Internacional de Ergonomia e Usabilidade de Interfaces Humano Computador

CINAHPA | 2017 - Congresso Internacional de Ambientes Hipermídia para Aprendizagem. afastamento do serviço. O painel obriga o usuário a inclinar demais a cabeça para verificação dos dados do sistema, tais como velocidade e combustível. O excesso de componentes sem uma preocupação com o que seria mais útil para o usuário fazer de acordo com as situações mais graves ou não, acarreta em um excesso de informações que deixa o usuário confuso na tomada de decisões durante sua pilotagem.

No plano B há uma linha da postura do membro superior adotada pelo motoqueiro. Percebe-se que ele mantem-se em uma postura ereta do tronco e ainda consegue acionar os dispositivos do guidão e utilizá-lo para direcionamento com o membro estendido em seu campo de alcance. Não há pressão sobre o membro superior, porém nessa posição, ao longo do dia pode implicar em forte cansaço nos ombros e dores nas costas.

Na figura 3 percebemos uma direção do olhar do usuário até o painel que fica acoplado ao guidão. Nota-se uma angulação maior que $30^{\circ}$ no pescoço, angulação tal que o usuário precisa fazer com a cabeça para ter em seu campo visual focal as informações do sistema da moto, quando o recomendado é de até $30^{\circ}$.

Figura 2: Inclinação da cabeça para visualizar informações do sistema.

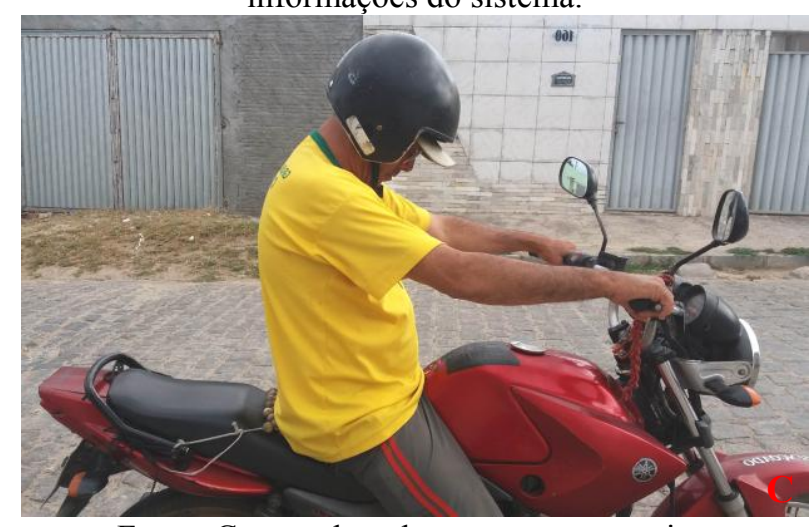

Fonte: Capturado pelo autor para pesquisa.

De acordo com IIDA (2005), é a partir dos $30^{\circ}$ de inclinação frontal da cabeça, em relação a vertical, que as dores no pescoço começam a ocorrer.

\subsection{Lista de Recomendações Ergonômicas}

As informações colhidas em cada etapa investigativa revelaram as seguintes demandas ergonômicas:

- $\quad$ Aumento da angulação do eixo formado pelas pegas do guidão em relação ao usuário visando à redução do desvio no punho;

- $\quad$ Adequação dos diâmetros da pega à mão humana;

- $\quad$ Revestimento da pega com textura para maior adesão da mão, evitando que a mão deslize involuntariamente da pega;

- $\quad$ Criação de uma segunda haste metálica entre as duas barras vertical-diagonal do guidão.

- Redução da jornada de trabalho visando à diminuição da sobrecarga muscular;

- $\quad$ Inserção de um programa de ginástica laboral a ser ministrado na sede dos mototaxistas, minimizando as consequências físicas da atividade;

\subsection{Etapas de Criação do Produto}

Considerou-se que o diâmetro da manopla deve ser maior na área que envolve os dedos polegares, indicadores e médios, e menor na área dos dedos anelares e mínimos. Levando em consideração os valores obtidos com os percentis antropométricos, percebeu-se a necessidade de se trabalhar com a dimensão do comprimento da mão de 20 centímetros, a fim de comportar toda a mão do homem, uma vez que se trata de uma pega prênsil de força (torque).

Aplicando fórmulas geométricas, verificou-se que o comprimento da mão poderia ser revertido em comprimento da circunferência $(20 \mathrm{~cm})$, a qual indicaria um diâmetro aproximado de $3 \mathrm{~cm}$ para a parte maior, o que coincide com as recomendações de Iida (2005) para o diâmetro de pega. Para a extremidade menor da pega, considerou-se a redução de $1 \mathrm{~cm}$ no diâmetro. A pega então é constituída por $3 \mathrm{~cm}$ de diâmetro para a extremidade interna e $2 \mathrm{~cm}$ para a extremidade externa. 
$16^{\circ}$ Ergodesign - Congresso Internacional de Ergonomia e Usabilidade de Interfaces Humano Tecnológica: Produto, Informações Ambientes Construídos e Transporte

$16^{\circ}$ USIHC - Congresso Internacional de Ergonomia e Usabilidade de Interfaces Humano Computador

CINAHPA | 2017 - Congresso Internacional de Ambientes Hipermídia para Aprendizagem.
Figura 3: Ilustração do formato planejado para a pega.

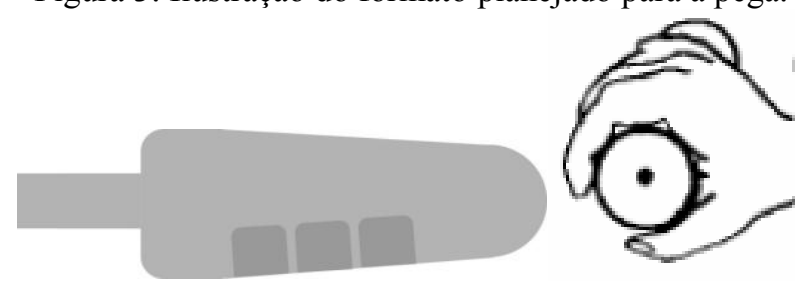

Fonte: Adaptado pelo autor da pesquisa.

Para que haja mais firmeza e segurança na pega, sugere-se um revestimento polímero com textura. A textura pode promover uma maior aderência entre a palma da mão e a superfície.

Para além da segurança no sistema, foram feitos e testados alguns modelos de estudo no intuito de testar as posturas de mão e punho, bem como os diâmetros da pega.

\subsection{Materiais}

A escolha dos materiais foi pensada para proteção do usuário e conservação do produto. Foi escolhido o aço inoxidável para modelagem dos tubos que formam o esqueleto/estrutura do guidão, pois possui baixa condutividade térmica, 52 W/MK diminuindo o aumento exponencial da temperatura do guidão. Sendo assim, a temperatura geral do guidão levará mais tempo para aumentar no clima quente e mais tempo para esfriar nos dias mais frios, buscando sempre manter a neutralidade e conforto para o usuário, além de evitar sobreaquecer os demais sistemas acoplados ao guidão.

Também foi selecionado o silicone emborrachado para revestimento da pega, uma vez que é resistente aos raios UV, proporciona maior conforto ao usuário visto a maciez do material, além de não conduzir a eletricidade caso aconteça alguma problema com o sistema da moto, além de fácil modelagem para ajuste ao formato da nova manopla descrita nesta pesquisa.

\subsection{Apresentação do Partido Projetual}

As medidas utilizadas respeitam a utilização dos dados antropométricos aqui citados, levando em consideração a distância do acento da motocicleta até o guidão, além de um projeto que permite ajuste na angulação do guidão para adequação com comprimento do membro superior do usuário. O painel da motocicleta recebe uma inclinação de 30 graus e uma base extra de sustentação para indicadores de velocidade e de gasolina, a fim de que o usuário não tenha que inclinar demais a cabeça para verificar as informações disponíveis a ele.

O projeto da pega recebeu uma inclinação pequena nas extremidades, adequandose à forma inclinada da mão fechada e mantendo o punho neutro. Também se buscou respeitar os diferentes diâmetros das extremidades da mão, considerando também o revestimento da manopla que agrega $3 \mathrm{~mm}$ ao diâmetro da pega, mantendo a dimensão dentro do limite máximo $(3,5 \mathrm{~cm})$ recomendado por Iida (2005).

Figura 4: Redesign da estrutura metálica do guidão.

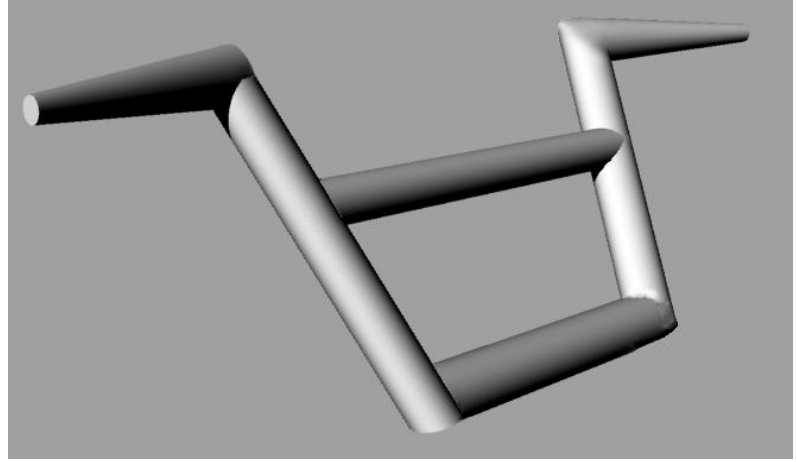

Fonte: Elaborado pelo autor para a pesquisa.

O guidão é composto por tubos de aço fundidos e cromados para estruturação do projeto desenvolvido, mantendo a sua base padrão para acoplagem à motocicleta.

\subsection{Dimensionamento Geral}

As dimensões gerais do guidão proposto podem ser acompanhadas pela figura 9 que se segue:

\section{Realização:}


$16^{\circ}$ Ergodesign - Congresso Internacional de Ergonomia e Usabilidade de Interfaces Humano Tecnológica: Produto, Informações Ambientes Construídos e Transporte

$16^{\circ}$ USIHC - Congresso Internacional de Ergonomia e Usabilidade de Interfaces Humano Computador

CINAHPA | 2017 - Congresso Internacional de Ambientes Hipermídia para Aprendizagem.
Figura 5: Vistas do guidão

\section{Vista Frontal}

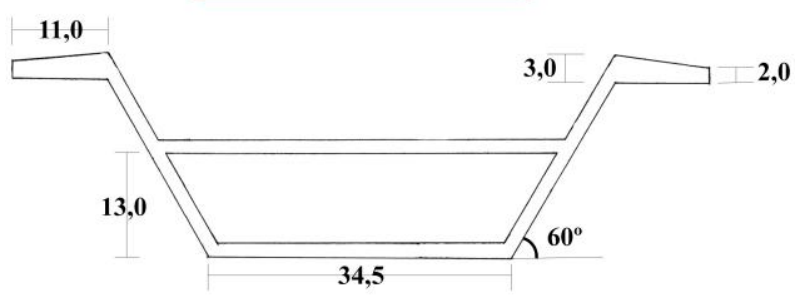

Vista Superior
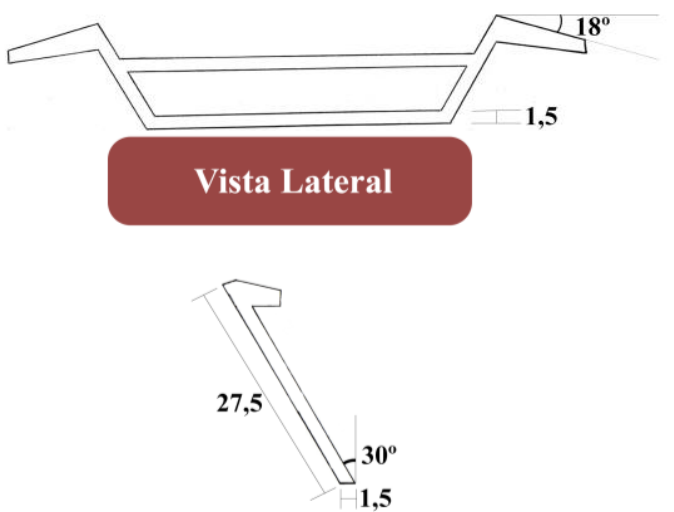

Fonte: Elaborada pelo autor para a pesquisa

Os tubos especificados para o projeto são de 1 1/4" de bitola, salvo a exceção das extremidades das pegas, as quais sofrem redução usinada de $1 \mathrm{~cm}$ em seu diâmetro.

\section{CONCLUSÕES}

O sistema-alvo deste trabalho, apesar de estruturalmente simples, apresentou grandes complexidades, visto todo o sistema maior no qual ele está envolvido, composto por muitas informações e acionamentos. Neste sentido, foram estipuladas mudanças, as quais alcançaram níveis significativos do ponto de vista dos problemas instrumentais, acionais e operacionais.

Com o projeto do novo guidão, buscouse a promoção da redução de incidência dos possíveis Distúrbios Osteomusculares Relacionados ao Trabalho. Salientamos que esta pesquisa focou na colaboração conceitual para o design do guidão da motocicleta analisada, como desdobramento complementar, notamos a necessidade de produção de um protótipo do projeto sugerido, visando novas avaliações.

O referente projeto repousou o olhar sobre o guidão da motocicleta, contudo, percebemos a importância de pesquisas complementares, as quais busquem análises dos demais sistemas do veículo. No modelo de moto investigado, Yamaha YBR 125 de 2011, identificamos outras possíveis fontes de inadequações, tal qual a questão do pedal, que pode estar gerando muito desconforto (fator identificado através do questionário aplicado).

Explorando outros elementos envolvidos na atividade, também percebemos a necessidade de intervenção sob os aspectos gerenciais dos mototaxistas da cidade.

Por fim, a pesquisa revela a necessidade de regulamentação da categoria na cidade em questão, onde, através de uma sindicalização, seria possível pleitear legalmente a formalidade da atividade e melhores condições de trabalho.

\section{REFERÊNCIAS}

FONTANA, R. T.; SILVA, M. B. da; OLIVEIRA, M. B. de. Atividade do mototaxista: riscos e fragilidades autorreferidos. Revista Brasileira de Enfermagem, Brasília, v. 64, n. 6, nov./dec. 2011.

\section{IBGE, FROTA MUNICIPAL DE VEÍCULOS. Disponível em:}

$<$ http://cidades.ibge.gov.br/painel/frota.php $>$ Acesso em: 01 fev. 2017.

IIDA, Itiro. Ergonomia - Projeto e Produção. 2. ed. São Paulo: Edgard Blucher, 2005. 630p.

MORAES, Anamaria de, MONT’ALVÃO, Cláudia. Ergonomia: conceitos e aplicações. Rio de Janeiro: 2AB, 2010. 232p.

PANERO, Julius. ZELNIK, Martin.

Dimensionamento Humano para Espaços

Interiores. Barcelona, Editorial Gustavo Gili/GG, 2008. 320p. 